\title{
Healthcare Workers Emotions, Perceived Stressors and Coping Strategies During a MERS-CoV Outbreak
}

\author{
Imran Khalid, MD, FCCP; Tabindeh J. Khalid, MD; Mohammed R. Qabajah, RN; \\ Aletta G. Barnard, RN; and Ismael A. Qushmaq, MD
}

\begin{abstract}
Objective: Healthcare workers (HCWs) are at high risk of contracting Middle East respiratory syndrome coronavirus (MERS-CoV) during an epidemic. We explored the emotions, perceived stressors, and coping strategies of healthcare workers who worked during a MERS-CoV outbreak in our hospital.
\end{abstract}

Design: A cross-sectional descriptive survey design.

Setting: A tertiary care hospital.

Participants: HCWs (I50) who worked in high risk areas during the April-May 2014 MERS-CoV outbreak that occurred in Jeddah, Saudi Arabia.

Methods: We developed and administered a "MERS-CoV staff questionnaire" to study participants. The questionnaire consisted of 5 sections with 72 questions. The sections evaluated hospital staffs emotions, perceived stressors, factors that reduced their stress, coping strategies, and motivators to work during future outbreaks. Responses were scored on a scale from 0-3. The varying levels of stress or effectiveness of measures were reported as mean and standard deviation, as appropriate.

Results: Completed questionnaires were returned by 117 (78\%) of the participants. The results had many unique elements. HCWs ethical obligation to their profession pushed them to continue with their jobs. The main sentiments centered upon fear of personal safety and well-being of colleagues and family. Positive attitudes in the workplace, clinical improvement of infected colleagues, and stoppage of disease transmission among HCWs after adopting strict protective measures alleviated their fear and drove them through the epidemic. They appreciated recognition of their efforts by hospital management and expected similar acknowledgment, infection control guidance, and equipment would entice them to work during future epidemics.

Conclusion: The MERS-CoV outbreak was a distressing time for our staff. Hospitals can enhance HCWs experiences during any future MERS-CoV outbreak by focusing on the above mentioned aspects.

Keywords: Healthcare workers; Emotions; Coping strategies; MERS-CoV

Corresponding Author: Imran Khalid, MD, FCCP, P.O. Box 40047,MBC J-102, King Fsaisal Specialist Hospital \& Research Center, Jeddah 21499, Saudi Arabia, Tel: +966504365564, Fax: + 14 | 36778932, Email: dr.imrankhalid@yahoo.com
Received:August 4, 2015

Revised: October 29, 2015

Accepted: January 14, 2016

doi: $10.3121 / \mathrm{cmr} .2016 .1303$ 
$\mathrm{A}$ s of July 24 2015, there have been 1,374 laboratoryconfirmed cases of infection with Middle East respiratory syndrome coronavirus (MERS-CoV) reported to the World Health Organization, with at least 490 related deaths, and the latest outbreak occurring in South Korea. ${ }^{1}$ The rate of secondary transmission seems to be low; $;^{2,3}$ however, those who contract the disease can get significantly sick. Studies have reported that the fatality rates range anywhere from $36 \%$ to $70 \%$ based on the underlying comorbidities and severity of pneumonia. ${ }^{3-5}$ Even people with no comorbidities can contract the disease and become critically ill. ${ }^{6,7}$ A major source of disease transmission has been linked to health care facilities, and health care workers exposed to cases of MERS$\mathrm{CoV}$ can contract both symptomatic and asymptomatic infection. ${ }^{4,8}$

A major outbreak of MERS-CoV occurred in the city of Jeddah, Saudi Arabia in the months of April to May 2014, almost 2 years after the first case of MERS-CoV was reported. ${ }^{8}$ During this outbreak, a large number of cases occurred among health care workers (HCW), which were contracted within the health care facilities. ${ }^{4,8}$ Some of the HCWs even died from the MERS-CoV disease. ${ }^{7}$ Moreover, it was reported that unrecognized, asymptomatic patients transferred MERS-CoV to their family or close contacts. ${ }^{9}$ All these factors were alarming and potentially distressing for the hospital staff who worked during the outbreak.

The severe acute respiratory syndrome (SARS) epidemic in 2003 also involved disease transmission to HCWs. ${ }^{10,11}$ Even though the fatality rates for SARS were lower than for the MERS-CoV infection, nonetheless, they were a cause of significant stress, emotional turmoil, and concern for all the SARS healthcare providers. ${ }^{1,3,10-14}$ The emotions, perceived stressors, and coping strategies of HCWs during the MERS$\mathrm{CoV}$ outbreak have not been explored. These issues were the intended focus of our study.

\section{Methods}

Ethical approval for the study was obtained from the Institutional Review Board of the hospital.

\section{Study Site}

The study was conducted among healthcare staff working in King Faisal Specialist Hospital \& Research Center, a tertiary care hospital in Jeddah, Saudi Arabia. The hospital is accredited by Joint Commission International (JCI) and Nurses Magnet Recognition Program. The hospital has a total of 420 beds, including 40 emergency room and 18 medical intensive care unit beds. During the outbreak, 40 confirmed cases of MERS$\mathrm{CoV}$ were treated in our hospital including, 23 hospital staff. There were 14 patients, including 3 hospital staff, who developed respiratory failure and required intubation and mechanical ventilation. Eight patients died from MERS-CoV pneumonia; however, all the infected hospital staff survived the illness.
Table 1. Hospital staff demographics $(n=117)$

\begin{tabular}{|c|c|}
\hline Characteristic & \\
\hline Age (years), mean (SD) & $38.55(8.01)$ \\
\hline \multicolumn{2}{|l|}{ Gender, n (\%) } \\
\hline Female & $89(76)$ \\
\hline Male & $28(24)$ \\
\hline \multicolumn{2}{|l|}{ Nationality, n (\%) } \\
\hline Philippines & $42(36)$ \\
\hline Indian & $15(13)$ \\
\hline Saudi & $14(12)$ \\
\hline North American & $12(10)$ \\
\hline Lebanese & $10(9)$ \\
\hline Jordanian & $7(6)$ \\
\hline Egyptian & $4(3)$ \\
\hline Other & $13(11)$ \\
\hline \multicolumn{2}{|l|}{ Place of Work, n (\%) } \\
\hline Critical Care Unit & $76(65)$ \\
\hline Emergency Medicine & $23(20)$ \\
\hline Outpatient Family Medicine & $18(15)$ \\
\hline \multicolumn{2}{|l|}{ Profession, n (\%) } \\
\hline Nurse & $89(76)$ \\
\hline Physician & $16(14)$ \\
\hline \multicolumn{2}{|l|}{ Respiratory Therapist 12 (10) } \\
\hline Clinical Experience (years), mean (SD) & $15.06(8.09)$ \\
\hline Employed at KFSHRC-J (years), mean (SD) & $7.21(3.76)$ \\
\hline Married, n (\%) & $100(85)$ \\
\hline Have Children, n (\%) & $97(83)$ \\
\hline Living with family at time of outbreak, n (\%) & $71(61)$ \\
\hline
\end{tabular}

Subjects

The main MERS-CoV outbreak in Jeddah Saudi Arabia occurred in April and May 2014. The hospital staff including nurses, physicians, and respiratory therapists who worked in high risk areas (intensive care unit, emergency department, and outpatient family medicine walk-in clinics) during the outbreak constituted our study population. We estimated these at-risk employees to be around 200.

\section{Study Tool}

The study tool was a comprehensive questionnaire derived and modified from the one used by Lee et $\mathrm{al}^{10}$ for the hospital staff during the 2003 SARS epidemic. We termed it "MERSCoV staff questionnaire". It consisted of 5 sections with 82 question items in English language. The survey was administered to ten hospital staff as a pilot. Based on their 
Table 2. Staff feelings during MERS-CoV outbreak who were directly involved in taking care of MERS-CoV patients ( $n=117$, Max score 3 )

\begin{tabular}{|c|c|c|c|}
\hline Number & Staff feelings during MERS-CoV outbreak & $\begin{array}{l}\text { Answered } \\
\text { Yes (\%) }\end{array}$ & $\begin{array}{l}\text { Average response score } \\
\text { mean (SD) }\end{array}$ \\
\hline 1 & $\begin{array}{l}\text { You felt that you had to do your job as it was your } \\
\text { professional and ethical duty }\end{array}$ & 94 & $2.58(0.89)$ \\
\hline 2 & You felt nervous and scared & 96 & $2.33(0.92)$ \\
\hline 3 & $\begin{array}{l}\text { You appreciated financial compensation after the } \\
\text { outbreak }\end{array}$ & 91 & $2.21(1.17)$ \\
\hline 4 & You were unhappy to do overtime & 93 & $2.19(0.86)$ \\
\hline 5 & $\begin{array}{l}\text { You appreciated special recognition for your job by the } \\
\text { Hospital administration }\end{array}$ & 88 & $2.02(1.15)$ \\
\hline 6 & $\begin{array}{l}\text { You expected financial compensation during the } \\
\text { outbreak }\end{array}$ & 81 & $1.93(1.13)$ \\
\hline 7 & $\begin{array}{l}\text { You tried curtailing your contact with the MERS-CoV } \\
\text { patient (e.g. shorten your trips to patients room) }\end{array}$ & 95 & $1.90(0.98)$ \\
\hline 8 & You thought of quitting your job & 92 & $1.83(0.93)$ \\
\hline 9 & $\begin{array}{l}\text { You felt that employees not directly exposed to MERS- } \\
\text { CoV avoided you }\end{array}$ & 82 & $1.67(1.25)$ \\
\hline 10 & $\begin{array}{l}\text { You noticed that employees outside your unit were } \\
\text { avoiding MERS-CoV patients }\end{array}$ & 85 & $1.56(1.09)$ \\
\hline 11 & $\begin{array}{l}\text { If optional, you would have chosen to work in a unit } \\
\text { where you would not be exposed to MERS-CoV }\end{array}$ & 74 & $1.16(1.29)$ \\
\hline 12 & $\begin{array}{l}\text { You would quit your job if MERS-CoV outbreak } \\
\text { recurred }\end{array}$ & 23 & $1.08(1.64)$ \\
\hline 13 & $\begin{array}{l}\text { You felt angry that your workload increased when } \\
\text { compared to employees not exposed to MERS-CoV }\end{array}$ & 70 & $1.07(1.06)$ \\
\hline 14 & You thought of calling in sick & 62 & $0.71(1.06)$ \\
\hline 15 & You called in sick at least once & 15 & $0.22(2.1)$ \\
\hline
\end{tabular}

Response Score Key; 0=Not At All; 1=Slightly; 2=Moderately; 3=Very Much

feedback and response, it was reduced to 72 items, and the wording of the questions was streamlined. The final printed version was administered to a convenience sample of 150 HCWs; participation was voluntary. All targeted staff worked in the high risk areas of the hospital where they were continuously exposed to patients with MERS-CoV during the outbreak. The staff dropped off the unmarked surveys anonymously in return boxes. The study questionnaire was administered 6 months after the MERS-CoV outbreak.

\section{Questionnaire Sections}

The first section of the questionnaire consisted of 15 questions that explored staff emotions during the MERS-CoV outbreak. Each question required a yes or no answer. Those who answered yes were then prompted to rate the severity of the feelings on a 4 -point scale $(0=$ not at all; $1=$ slight; $2=$ moderate; $3=$ very much). The internal consistency coefficients were 0.79 (Kuder-Richardson Formula 20) for the score on their feelings and 0.76 (Cronbach's $\alpha$ ) for the severity of feelings.

The second section evaluated 20 different possible factors that could have caused stress among the staff. It also required a yes or no response. Those who answered yes responded further regarding the severity of the stress factor $(0=$ very minimal; $1=$ slight $; 2=$ moderate; $3=$ very much). The internal consistency coefficients were 0.81 (Kuder-Richardson Formula 20) for the number of stressors and 0.83 (Cronbach's $\alpha$ ) for the stress severity.

The third section of the questionnaire had 14 queries looking at the various factors that were made available to the hospital staff, either directly or indirectly, and could have helped reduce their stress. These questions were also answered on a 4-point scale $(0=$ not at all effective; $1=$ mildly effective; $2=$ moderately effective; $3=$ extremely effective). The internal consistency coefficient (Cronbach's $\alpha$ ) for the degree of effectiveness was 0.86 .

Section four, consisting of 13 questions, looked at different personal coping strategies that the staff could have used. It also comprised firstly a yes or no response. Those who answered yes then rated the strategies from $0-4(0=$ never; $1=$ sometimes; $2=$ often; $3=$ always). The internal consistency coefficients were 0.71 (Kuder-Richardson Formula 20) for the number of stressors and 0.78 (Cronbach's $\alpha$ ) for the rating of coping strategies. 
Table 3. Questions regarding factors that caused stress among staff during MERS-CoV outbreak ( $n=117$, Maximum score 3)

\begin{tabular}{|c|c|c|c|}
\hline Number & Factor causing stress & $\begin{array}{l}\text { Staff answered } \\
\text { Yes (\%) }\end{array}$ & $\begin{array}{l}\text { Level of stress } \\
\text { mean (SD) }\end{array}$ \\
\hline 1 & Seeing your colleagues getting intubated & 96 & $2.77(0.63)$ \\
\hline 2 & You could transmit MERS-CoV to your family or friends & 94 & $2.69(0.62)$ \\
\hline 3 & $\begin{array}{l}\text { Small mistake or lapse in concentration could infect you or } \\
\text { others }\end{array}$ & 87 & $2.66(0.66)$ \\
\hline 4 & Taking care of your own colleagues sick from MERS-CoV & 88 & $2.54(0.81)$ \\
\hline 5 & Seeing patients with MERS-CoV dying in front of you & 85 & $2.54(0.73)$ \\
\hline 6 & $\begin{array}{l}\text { Not knowing when the MERS-CoV outbreak will be under } \\
\text { control }\end{array}$ & 91 & $2.51(0.78)$ \\
\hline 7 & Every time you were exposed to a new MERS-CoV patient & 88 & $2.49(0.76)$ \\
\hline 8 & Lack of treatment for MERS-CoV & 83 & $2.48(0.78)$ \\
\hline 9 & $\begin{array}{l}\text { News of new cases of MERS-CoV reported in TV/ } \\
\text { newspaper }\end{array}$ & 84 & $2.45(0.83)$ \\
\hline 10 & You were emotionally exhausted & 86 & $2.45(0.81)$ \\
\hline 11 & You had physical stress/fatigue & 77 & $2.42(0.81)$ \\
\hline 12 & Colleagues displaying MERS-like symptoms & 92 & $2.42(0.8)$ \\
\hline 13 & $\begin{array}{l}\text { You developed respiratory symptoms and feared that you } \\
\text { had MERS-CoV }\end{array}$ & 64 & $2.42(0.79)$ \\
\hline 14 & $\begin{array}{l}\text { You could get MERS-CoV infection from a patient in the } \\
\text { hospital }\end{array}$ & 88 & $2.40(1)$ \\
\hline 15 & Conflict between your duty and your own safety & 75 & $2.36(0.85)$ \\
\hline 16 & Seeing your colleagues stressed or afraid & 58 & $2.31(1)$ \\
\hline 17 & Getting screened for MERS-CoV infection after exposure & 74 & $2.26(0.92)$ \\
\hline 18 & $\begin{array}{l}\text { You felt there were not adequate protective measures } \\
\text { (including enough negative pressure rooms) }\end{array}$ & 60 & $2.17(0.99)$ \\
\hline 19 & You had to wear protective gear on a daily basis & 86 & $2.17(0.91)$ \\
\hline 20 & Shortage of staff at times & 70 & $2.07(0.91)$ \\
\hline
\end{tabular}

Scoring for Level Of Stress; 0=Very Minimal Stress; 1=Slightly Stressed; 2=Moderately Stressed; 3=Very Much Stressed

The fifth section consisted of 10 possible incentives that could promote willingness to participate in any future MERS-CoV or other epidemic. These were rated on a 4 -point scale $(0=$ not at all important to $4=$ most important).

\section{Data Analyses}

Descriptive statistics were used to elaborate the data collected from the survey. Correlational analysis was performed to evaluate the internal consistency of the "MERS-CoV staff questionnaire". The varying levels of stress or effectiveness of measures were reported as mean and standard deviation, as appropriate.

\section{Results}

Of the eligible staff, 117 (78\%) returned the questionnaire. The remainder either did not turn in the questionnaire or returned it incomplete and were, therefore, excluded. Demographics of the staff are outlined in Table 1. Respondents were mostly non-native work force belonging to a heterogeneous ethnic background, and the majority was married, living with families.

Section 1, which explored the emotions of the staff, yielded some interesting results (Table 2). Among the factors to which more than $80 \%$ of staff answered yes, the most important element was the innate professional and ethical obligation that drove staff to continue working during the epidemic. The staff, however, did feel fearful during the outbreak. They appreciated the extra financial compensation and recognition given to them by the hospital. They tried to limit their exposure to patients with MERS-CoV, and were reluctant to work overtime. In case a MERS-CoV outbreak recurred, most of them were willing to continue working after their initial experience.

The answers in section 2 of the questionnaire, which looked at the different stress factors, were categorized in order of the impact of the factor (Table 3). The main stressors were 
Table 4. Factors that helped in reducing stress during MERS-CoV outbreak ( $n=117$, Maximum score 3 )

\begin{tabular}{clc}
\hline Number & Factors that helped to reduce stress & Mean (SD) \\
\hline 1 & Positive attitude from colleagues in your department & $2.34(0.74)$ \\
2 & None of the staff getting MERS after starting strict protective measures & $2.34(0.82)$ \\
3 & Improvement in patient's condition & $2.30(0.91)$ \\
4 & Your colleagues who were infected getting better & $2.28(0.78)$ \\
5 & Protective equipment provided to you by Hospital & $2.10(0.86)$ \\
6 & Clear guidelines from Hospital for infection prevention & $2.07(1.01)$ \\
7 & Your family members or friends outside hospital did not get MERS-CoV & $1.97(1.15)$ \\
8 & Decrease in MERS-CoV cases reported in news & $1.94(0.99)$ \\
9 & Likelihood that you would get extra compensation for your exposure to MERS-CoV & $1.90(1.18)$ \\
10 & All healthcare professionals working together on front line & $1.60(1.05)$ \\
11 & Confidence in the hospital staff in case you got sick from MERS-CoV & $1.58(1.12)$ \\
12 & Not to do overtime & $1.52(1.08)$ \\
13 & Sharing jokes or humor among colleagues & $1.43(1.04)$ \\
14 & Getting free meals from the hospital in your unit & $1.19(1.16)$ \\
\hline
\end{tabular}

0=Not At All effective; 1=Mildly Effective; 2=Moderately Effective; 3=Extremely Effective in Reducing Stress

related to staffs' own safety as well as safety of colleagues and family. Seeing colleagues contracting the infection, getting sicker, and being intubated for respiratory failure was very distressing. Caring for these sick colleagues also put them under enormous emotional burden.

There are various factors that can directly or indirectly help reduce stress during a MERS-CoV outbreak, and these are evaluated in Section 3 (Table 4). Positive attitude in the workplace was the biggest impact in reducing staff stress. Moreover, infected colleagues getting better, adequate provision of protective equipment, and drop in disease transmission after strict infection control practices eased the anxiety of the staff.

As expected, all of the staff used some sort of personal coping strategies. Section 4 of questionnaire gives some insight into these strategies (Table 5). Staff followed very strict infection control practices with universal precautions, used disposable scrubs for work, minimized their outside exposure, and were involved in supportive measures either personally or with family.

Finally in the fifth section, we asked the staff about motivators to continue working during any future MERS-CoV or other infectious disease outbreak. The staff expected similar provision of personal protective equipment, availability of a possible cure for the disease, provision of disability benefits, and family support.

\section{Discussion}

Healthcare workers are at the front line of any given epidemic and risk their lives in the line of duty ${ }^{15}$ These hospital staff are under huge stress not only during the epidemic, but they can also suffer from long-term psychological consequences. This was evident with the SARS outbreak and most recently with the Ebola virus outbreak. ${ }^{16,17}$ However, each outbreak of an infectious disease differs in its geographical location, pathogenesis, transmissibility, infectivity, and fatality. No two disease outbreaks are alike, and each has its own unique impact on the hospital staff facing that disease. ${ }^{16,17}$ Our study is among the first of its kind to explore the emotions, perceived stressors, and coping strategies of the HCWs who faced the deadly MERS-CoV outbreak.

During a respiratory illness outbreak all hospital workers are exposed to some risk of infection; however, the extent of this risk is not distributed equally. Some specialties, like emergency room and critical care staff, are likely to be at a higher risk than those in unrelated or non-acute specialties. ${ }^{15}$ For this reason, we targeted HCWs from these high risk areas in our study. We only included nurses, respiratory therapists, and physicians in our study and did not include other staff like housekeepers, unit clerks, etc., as they were not assigned to these high risk areas on a continuous basis. The hospital staff in our institution were from a diverse ethnic background, which follows the general trend in Saudi Arabia, where most of healthcare work force is non-indigenous. ${ }^{18}$ Even though our questionnaire was very comprehensive, nonetheless, the response rate of $78 \%$ was in line with published data. ${ }^{19}$

Our results show that the staff experienced emotional turmoil during the MERS-CoV epidemic. The anxiety and nervousness felt by our staff are common in any epidemic, although their intensity varies. ${ }^{20}$ Expectation of extra compensation, special recognition, and avoidance of overtime during a disaster were 
Table 5. Personal coping strategies used by the staff to alleviate stress ( $n=117$, Maximum score 3 )

\begin{tabular}{|c|c|c|c|}
\hline Number & Strategy used by staff & $\begin{array}{l}\text { Responded } \\
\text { Yes (\%) }\end{array}$ & Mean (SD) \\
\hline 1 & $\begin{array}{l}\text { Followed strict personal protective measures (e.g., mask, gown, hand } \\
\text { washing etc.) }\end{array}$ & 99 & $2.82(0.53)$ \\
\hline 2 & $\begin{array}{l}\text { Kept separate clothes for work/used disposable scrubs provided by } \\
\text { Hospital to minimize transmission }\end{array}$ & 94 & $2.76(0.67)$ \\
\hline 3 & $\begin{array}{l}\text { Considered every patient admitted to the hospital as having MERS-CoV } \\
\text { infection and using full protective gear even if patient was MERS-CoV } \\
\text { negative }\end{array}$ & 96 & $2.63(0.69)$ \\
\hline 4 & Read about MERS-CoV, its prevention and mechanism of transmission & 89 & $2.18(0.93)$ \\
\hline 5 & Avoided going out in public places to minimize exposure from MERS-CoV & 90 & $2.13(0.89)$ \\
\hline 6 & Did relaxation activities, e.g., involved in prayers, sports, exercise etc. & 81 & $2.13(0.98)$ \\
\hline 7 & Chatted with family and friends to relieve stress and obtain support & 87 & $1.93(0.99)$ \\
\hline 8 & $\begin{array}{l}\text { Talking to yourself and motivating to face the MERS-CoV outbreak with } \\
\text { positive attitude }\end{array}$ & 75 & $1.87(1.04)$ \\
\hline 9 & $\begin{array}{l}\text { Got help from family physicians or other doctors to reduce your stress and } \\
\text { get reassurance }\end{array}$ & 59 & $1.37(1.19)$ \\
\hline 10 & $\begin{array}{l}\text { Tried to be busy at home in activities that would keep your mind away } \\
\text { from MERS-CoV }\end{array}$ & 61 & $1.24(1.08)$ \\
\hline 11 & $\begin{array}{l}\text { Avoided doing overtime to reduce exposure to MERS-CoV patients in } \\
\text { hospital }\end{array}$ & 74 & $1.21(0.98)$ \\
\hline 12 & Avoided media news about MERS-CoV and related fatalities & 56 & $0.74(0.89)$ \\
\hline 13 & Vented emotions by crying, screaming etc. & 39 & $0.68(1.01)$ \\
\hline
\end{tabular}

Scoring key for using strategies: 0=Never Used; 1=Sometimes Used; 2=Often Used; 3=Always Used

strongly anticipated by our staff, as reported in other disease epidemics. ${ }^{10,21,22}$ However, the most important emotion that drove them to continue working was their ethical and professional obligation towards their profession.

Among the various stressors related to the MERS-CoV outbreak, safety was the main concern for the staff. It was extremely stressful for them to see their colleagues getting intubated, patients dying in front of them from MERS-CoV, as well as the fear that they could transmit the disease to their families or friends. These factors were seen among HCWs who faced SARS, but with lesser intensity. ${ }^{10}$ The hospital staff in our study was also concerned about the duration of the epidemic and lack of treatment for the disease. Hospitals should focus on interventions to communicate risk and promote disease mitigation measures in epidemics, providing psychological support to the staff. ${ }^{23,24}$ This was evident from our staff responses in which they appreciated the impact of strict infection control practice guidance and provision of personal protective equipment in alleviating their stress.

Two main factors that helped ease the stress of the healthcare workers were positive attitude from colleagues and the fact that the nosocomial transmission of MERS-CoV completely stopped after adopting strict precautions. Positive attitude at work results in improved quality of care.$^{25}$ An environment of optimism and assurance of personal safety led our staff to carry on with their work during the MERS-CoV crisis, and these two factors can be key in retaining staff during an epidemic.

The coping strategies used by our staff also give an insight into the MERS-CoV epidemic. Using stringent protective measures universally for all patients, using disposable scrubs at work, and minimizing outside exposure in the form of semiquarantine, reflects the extreme caution they used. This cautiousness is the cornerstone of dealing with any epidemic. ${ }^{26}$

In 2015, South Korea faced a deadly MERS-CoV outbreak, and another epidemic could recur in the Middle East. When asked about the factors that would incentivize staff to continue working during any future epidemics, factors related to safety, disease knowledge, special compensation, and recognition were the dominant motivators. Some of these factors reflect what has been reported in other epidemics. ${ }^{10,15}$

Our study has a few limitations. The sample size was not large enough to focus on HCWs by profession or distinguish their responses based on place of work. It was done 6 months after the outbreak ended, which could result in recall bias (this could underestimate or overestimate response severity) and selection bias. The survey obviously could miss the responses of employees who quit during the outbreak. It is a single center experience in a Magnet-recognized and JCI-accredited hospital. The results could vary in smaller non-accredited hospitals. The work force belonged to diverse ethnic 
Table 6. Motivational factors to encourage continuation of work in future outbreaks $(n=117$, Maximum score=3)

\begin{tabular}{cll}
\hline Number & Motivational factors for future outbreaks & $\begin{array}{c}\text { Importance factor } \\
\text { Mean (SD) }\end{array}$ \\
\hline 1 & Similar adequate personal protective equipment supply by the Hospital & $2.88(0.41)$ \\
2 & Available cure or vaccine for the disease & $2.85(0.35)$ \\
3 & Family support & $2.71(0.64)$ \\
4 & Compensation to family if disease related death at work & $2.74(0.71)$ \\
5 & Financial recognition of efforts & $2.64(0.75)$ \\
6 & Disability benefits if disabled from the disease & $2.55(0.77)$ \\
7 & Recognition from management and supervisors for the extra efforts & $2.27(0.99)$ \\
8 & Psychiatric help and therapy made available in work place to help reduce stress and anxiety \\
9 & Not forced to do overtime & $1.72(1.16)$ \\
10 & Reduced working hours during outbreaks & $1.67(1.22)$ \\
\hline $0=$ Not important at all; 3=Most important
\end{tabular}

backgrounds, but one can also argue to consider this factor as strength of the study.

Future studies should focus on elaborating further on our findings. We suggest increasing the staff sample size in any future MERS-CoV or other infectious outbreaks, involving other professions like housekeeping, and categorizing the experiences based on profession. This would answer some pending questions, for example, whether nurses get more worried than physicians, or perhaps those with prior outbreak experience or better training are less worried than those with no experience or limited training. Also, what disease characteristics do staff find most concerning (e.g., mode of transmission, case fatality rate, etc.)? Answers to these questions would further help hospitals mitigate potential challenges they face with staff protection, retention, and satisfaction during these difficult events.

\section{Conclusion}

The 2014 MERS-CoV outbreak in Jeddah, Saudi Arabia caused emotional distress among the HCWs. The feelings of HCWs, their perceived stressors, and coping strategies had some unique elements. The main sentiments centered upon personal safety and safety of colleagues and family, positive attitudes in the work place, availability of strict infection control guidelines and equipment, recognition, and monetary compensation. Hospitals can enhance the HCWs experience during any future MERS-CoV outbreak by focusing on these aspects.

\section{References}

1. World Health Organization. Emergencies preparedness, response. Middle East respirator syndrome coronavirus (MERS-CoV) Saudi Arabia. 2015. Available at: http://www.who.int/csr/ don/24-july-2015-mers-saudi-arabia/en/
2. Drosten C, Meyer B, Müller MA, Corman VM, Al-Masri M, Hossain R, Madani H, Sieberg A, Bosch BJ, Lattwein E, Alhakeem RF, Assiri AM, Hajomar W, Albarrak AM, Al-Tawfiq JA, Zumla AI, Memish ZA. Transmission of MERS-coronavirus in household contacts. N Engl J Med 2014;371:828-835.

3. Arabi YM, Arifi AA, Balkhy HH, Najm H, Aldawood AS, Ghabashi A, Hawa H, Alothman A, Khaldi A, Al Raiy B. Clinical course and outcomes of critically ill patients with Middle East respiratory syndrome coronavirus infection. Ann Intern Med 2014;160:389397.

4. Oboho IK, Tomczyk SM, Al-Asmari AM, Banjar AA, Al-Mugti H, Aloraini MS, Alkhaldi KZ, Almohammadi EL, Alraddadi BM, Gerber SI, Swerdlow DL, Watson JT, Madani TA. 2014 MERS-CoV outbreak in Jeddah--a link to health care facilities. N Engl J Med 2015;372:846-854.

5. Saad M, Omrani AS, Baig K, Bahloul A, Elzein F, Matin MA, Selim MA, Al Mutairi M, Al Nakhli D, Al Aidaroos AY, Al Sherbeeni N, Al-Khashan HI, Memish ZA, Albarrak AM. Clinical aspects and outcomes of 70 patients with Middle East respiratory syndrome coronavirus infection: a singlecenter experience in Saudi Arabia. Int J Infect Dis 2014;29:301-306.

6. Alghamdi IG, Hussain II, Almalki SS, Alghamdi MS, Alghamdi MM, El-Sheemy MA. The pattern of Middle East respiratory syndrome coronavirus in Saudi Arabia: a descriptive epidemiological analysis of data from the Saudi Ministry of Health. Int J Gen Med 2014;7:417-423.

7. Al-Hameed F, Wahla AS, Siddiqui S, Ghabashi A, Al-Shomrani M, Al-Thaqafi A, Tashkandi Y. Characteristics and Outcomes of Middle East Respiratory Syndrome Coronavirus Patients Admitted to an Intensive Care Unit in Jeddah, Saudi Arabia. J Intensive Care Med 2015 Apr 9. pii: 0885066615579858. [Epub ahead of print]

8. Assiri A, McGeer A, Perl TM, Price CS, Al Rabeeah AA, Cummings DA, Alabdullatif ZN, Assad M, Almulhim A, Makhdoom H, Madani H, Alhakeem R, Al-Tawfiq JA, Cotten M, Watson SJ, Kellam P, Zumla AI, Memish ZA. Hospital outbreak of Middle East respiratory syndrome coronavirus. N Engl J Med 2013;369:407-416. 
9. Omrani AS, Matin MA, Haddad Q, Al-Nakhli D, Memish ZA, Albarrak AM. A family cluster of Middle East Respiratory Syndrome Coronavirus infections related to a likely unrecognized asymptomatic or mild case. Int J Infect Dis 2013;17:e668-e672.

10. Lee SH, Juang YY, Su YJ, Lee HL, Lin YH, Chao CC. Facing SARS: psychological impacts on SARS team nurses and psychiatric services in a Taiwan general hospital. Gen Hosp Psychiatry 2005;27:352-358.

11. Varia M, Wilson S, Sarwal S, McGeer A, Gournis E, Galanis E, Henry B; Hospital Outbreak Investigation Team. Investigation of a nosocomial outbreak of severe acute respiratory syndrome (SARS) in Toronto, Canada. CMAJ 2003;169:285-292.

12. Styra R, Hawryluck L, Robinson S, Kasapinovic S, Fones C, Gold WL. Impact on health care workers employed in high-risk areas during the Toronto SARS outbreak. J Psychosom Res 2008;64:177-183.

13. Shiao JS, Koh D, Lo LH, Lim MK, Guo YL. Factors predicting nurses' consideration of leaving their job during the SARS outbreak. Nurs Ethics 2007;14:5-17.

14. Maunder RG, Lancee WJ, Balderson KE, Bennett JP, Borgundvaag B, Evans S, Fernandes CM, Goldbloom DS, Gupta M, Hunter JJ, McGillis Hall L, Nagle LM, Pain C, Peczeniuk SS, Raymond G, Read N, Rourke SB, Steinberg RJ, Stewart TE, VanDeVelde-Coke S, Veldhorst GG, Wasylenki DA. Long-term psychological and occupational effects of providing hospital healthcare during SARS outbreak. Emerg Infect Dis 2006;12:19241932.

15. Simonds AK, Sokol DK. Lives on the line? Ethics and practicalities of duty of care in pandemics and disasters. Eur Respir J 2009;34:303-309.

16. Lin CY, Peng YC, Wu YH, Chang J, Chan CH, Yang DY. The psychological effect of severe acute respiratory syndrome on emergency department staff. Emerg Med J 2007;24:12-7.

17. Lehmann M, Bruenahl CA, Löwe B, Addo MM, Schmiedel S, Lohse AW, Schramm C. Ebola and psychological stress of health care professionals. Emerg Infect Dis. 2015;21:913-914.

18. Aldossary A, While A, Barriball L. Health care and nursing in Saudi Arabia. Int Nurs Rev 2008;55:125-128.

19. Bolt EE, van der Heide A, Onwuteaka-Philipsen BD. Reducing questionnaire length did not improve physician response rate: a randomized trial. J Clin Epidemiol 2014;67:477-481.

20. Liao Q, Cowling BJ, Lam WW, Ng DM, Fielding R. Anxiety, worry and cognitive risk estimate in relation to protective behaviors during the 2009 influenza A/H1N1 pandemic in Hong Kong: ten cross-sectional surveys. BMC Infect Dis 2014;14:169.

21. Ly T, Selgelid MJ, Kerridge I. Pandemic and public health controls: toward an equitable compensation system. J Law Med 2007;15:296-302.

22. Baumann AO, Blythe JM, Underwood JM. Surge capacity and casualization: Human resource issues in the postSARS health system. Can J Public Health 2006;97:230-232.

23. Schiavo R, May Leung M, Brown M. Communicating risk and promoting disease mitigation measures in epidemics and emerging disease settings. Pathog Glob Health 2014;108:7694.

24. Wu P, Fang Y, Guan Z, Fan B, Kong J, Yao Z, Liu X, Fuller CJ, Susser E, Lu J, Hoven CW. The psychological impact of the SARS epidemic on hospital employees in China: exposure, risk perception, and altruistic acceptance of risk. Can J Psychiatry. 2009;54:302-311.

25. Klein J, Grosse Frie K, Blum K, von dem Knesebeck O. Psychosocial stress at work and perceived quality of care among clinicians in surgery. BMC Health Serv Res 2011;11:109.
26. Faye O, Boëlle PY, Heleze E, Faye O, Loucoubar C, Magassouba N, Soropogui B, Keita S, Gakou T, Bah el HI, Koivogui L, Sall AA, Cauchemez S. Chains of transmission and control of Ebola virus disease in Conakry, Guinea, in 2014: an observational study. Lancet Infect Dis 2015;15:320-326.

\section{Author Affiliations}

Imran Khalid, MD, FCCP*; Tabindeh J. Khalid, MD*; Mohammed R. Qabajah, RN*; Aletta G. Barnard, RN*; and Ismael A. Qushmaq, MD*

*King Faisal Specialist Hospital \& Research Center, Jeddah, Saudi Arabia 